\title{
EL TURISMO COMO FACTOR ESTRATÉGICO DE DESARROLLO RURAL: EL CAMINO DE SANTIAGO FRANCÉS
}

\author{
María José Andrade Suárez \\ Grial Leira Landeira \\ Rosa Caramés Valo'
}

Universidade da Coruña

\begin{abstract}
Resumen: El potencial turístico adquiere cada vez una mayor importancia como motor dinamizador de las zonas rurales que, inmersas en una profunda crisis económica y social, disponen de un enorme patrimonio natural y cultural. De acuerdo con este planteamiento, la red de los Caminos de Santiago puede ser considerada como una buena prueba de ello. Bajo esta premisa, se trata de estudiar en la presente investigación la potencialidad del Camino de Santiago Francés como alternativa para el desarrollo socioeconómico de los espacios rurales por los que transcurre. La hipótesis inicial se basa en que esta modalidad de turismo ha servido para relanzar el desarrollo socioeconómico de los municipios rurales camineros.

Se analizarán los resultados a partir de los datos referidos al tramo gallego del Camino Francés, la ruta principal y más frecuentada, que abarca un total de catorce municipios pertenecientes a las provincias de Lugo y A Coruña en el período comprendido entre 1991 y 2005. Las variables objeto de examen seleccionadas como indicadores de la acción dinamizadora del Camino corresponden al movimiento demográfico, la cuota de mercado y el número de licencias comerciales, así como el índice turístico.

Palabras clave: Camino de Santiago Francés, peregrinaje, municipios rurales, desarrollo social y económico, desarrollo turístico.
\end{abstract}

Resumo: O turismo como factor estratéxico de desenvolvemento rural: o Camiño de Santiago francés

O potencial turístico adquire cada vez unha maior importancia como motor dinamizador das zonas rurais que, inmersas nunha profunda crise económica e social, disponen dun enorme patrimonio natural e cultural. De acordo con esta formulación, a rede dos Camiños de Santiago pode ser considerada como unha boa proba diso. Baixo esta premisa, trátase de estudar nesta investigación a potencialidade do Camiño de Santiago francés como alternativa para

1 María José Andrade Suárez: mandrade@udc.es; Grial Leira Landeira: grialleira@gmail.com; Rosa Caramés Valo: carames@udc.es 
o desenvolvemento socioeconómico dos espazos rurais polos que transcorre. A hipótese inicial baséase en que esta modalidade de turismo serviu para relanzar o desenvolvemento socioeconómico dos municipios rurais camiñeiros.

Analizaranse os resultados a partir dos datos referidos ao tramo galego do Camiño francés, a ruta principal e máis frecuentada, que abrangue un total de catorce municipios pertencentes ás provincias de Lugo e A Coruña no período comprendido entre 1991 e 2005. As variables obxecto de exame seleccionadas como indicadores da acción dinamizadora do Camiño corresponden ao movemento demográfico, a cota de mercado e o número de licenzas comerciais, así como o índice turístico.

Palabras clave: Camiño de Santiago francés, peregrinación, municipios rurais, desenvolvemento social e económico, desenvolvemento turístico.

\begin{abstract}
Tourism as a strategic factor in rural development: The French Camino de Santiago (The Way of St James)

Tourism is increasingly important as an engine for stimulating the development of rural areas which, although immersed in a severe economic and social crisis, have an enormous natural and cultural heritage. The Caminos de Santiago network can be considered a good example of this. From this initial starting point, the research studies the potential of the French Camino de Santiago to be an alternative source of socioeconomic development for the rural areas through which it runs. The initial hypothesis is based on the idea that this type of tourism has served to relaunch the socioeconomic development of the rural municipalities along the route.

The results will be analysed using data relating to the Galician stretch of the French Camino, the main route and the one most heavily frequented. This includes a total of fourteen municipal areas belonging to the provinces of Lugo and A Coruña and the data are for the period running from 1991 to 2005. The variables selected for study as indicators of the stimulating effect of the Camino relate to the demographic dynamics, market share and number of commercial licenses as well as the tourist index.
\end{abstract}

Key words: French Camino de Santiago, pilgrimage, rural municipalities, social and economic development, tourist development

\title{
1. INTRODUCCIÓN
}

El Camino de Santiago constituye un complejo fenómeno que abarca un amplio conjunto de perspectivas (económico, territorial, espiritual, sociológico, etc.) en el que se combinan diversas variables: arquitectónicas, medioambientales, económicas, sociales, culturales, turísticas, etc. cuya imbricación y superposición las dota de un atractivo especial. Por tanto, cabe destacar que las peregrinaciones constituyen una modalidad actual de turismo, en concreto, de turismo religioso.

El Camino de Santiago es un bien, un patrimonio y un símbolo que durante siglos ha permanecido vivo, si bien es cierto que décadas atrás había sufrido un proceso de desvalorización, tanto en lo material como en lo simbólico, Iglesia, Gobierno y multitud de particulares contribuyeron a que a partir de la década de los ochenta a que este proceso revirtiese sus efectos. En este sentido, se comenzaron a realizar numerosas estrategias de revitalización y se pusieron en marcha diversos programas, como los del Xacobeo 93, 99 y 2004 para ayudar a la recuperación de los municipios por los que transcurre el Camino de Santiago, apoyando tanto a las corporaciones 
municipales en la revitalización, señalización y limpieza de los trazados, como a las entidades e individuos particulares (como las Asociaciones de Amigos del Camino) en sus iniciativas alrededor de este bien cultural.

Es preciso recordar a modo de ejemplo tres hechos: el papel de la Xunta de Galicia en la promoción del Xacobeo 93, 99 y 2004, el papel dinamizador de las Asociaciones de Amigos del Camino y el reconocimiento en 1987, por parte del Consejo de Europa, del Camino de Santiago como Primer Itinerario Cultural Europeo.

Prueba de la importancia de este Plan fue que el año 1993 atrajo a Santiago de Compostela en torno a los tres millones de visitantes, en el año 1999 se volvió a repetir la gran afluencia con un total de cinco millones de visitantes y el año 2004 fue de nuevo otra vez un éxito con más de seis millones de visitantes.

En este contexto, cabe añadir que la concepción originaria del Camino como una modalidad de turismo religioso ha ido evolucionando hacia un significado cultural más dilatado, aportando así una nueva dimensión, es decir, como factor de desarrollo local de los espacios rurales por donde pasa el Camino.

Se trata de estudiar, por tanto, en esta investigación, la potencialidad del Camino de Santiago como alternativa para el desarrollo socioeconómico de los espacios rurales por los que transcurre. El presente trabajo se centra en la Ruta Francesa, la cual recorre algunos de los municipios y comarcas más deprimidas de Galicia. El centrarse en el Camino Francés se debe tanto a que es la ruta más estudiada y más conocida como al hecho de que coincida con la vía de penetración más frecuentada y con mayor intensidad de flujos de peregrinos.

Bajo el prisma de estas reflexiones, se ha realizado esta investigación, planteando en primer lugar los aspectos teóricos y conceptuales que permiten explicar la crisis del mundo rural y el papel del turismo como opción de desarrollo de las áreas rurales en el contexto de una "nueva ruralidad".

\section{LA NUEVA RURALIDAD: EL TURISMO COMO OPCIÓN DE DESARRO- LLO RURAL}

El estudio del mundo rural conduce inmediatamente a la conclusión de que este medio está sufriendo una fuerte crisis que presenta, de modo esquemático, una triple perspectiva (García Docampo, 2003: 206): demográfica, económica y cultural. Los rasgos citados son un extracto de lo que tiene lugar a nivel nacional pero, para el caso de Galicia, pueden ser detalladas las siguientes características (García Docampo, 2003: 208):

- Incremento del número de municipios menores de 2.500 habitantes debido a las pérdidas de efectivos poblacionales en los "municipios marginales"

- Disminución de a población empleada en el sector primario 
- El sector agrario continúa teniendo un fuerte peso en la economía gallega, a cual motiva que toda la crisis agraria se traslade a la economía gallega en general

- Fuerte peso de las tierras "no trabajadas" en el sector agrario.

- La parcelación se caracteriza por un fuerte minifundismo

- Persiste una tipología de explotación de carácter muy marginal

- Escaso peso de la burguesía pobre en el sector

- Fuerte peso de las tierras de difícil mecanización y rentabilización

- Desaparición de los elementos idiosincrásicos del mundo y de la cultura rural

El contexto global presiona, por tanto, para instaurar nuevos modos de aprovechamiento del espacio rural (González Fernández, 1999:135). Nos encontramos, pues, ante un creciente interés por el futuro de los espacios rurales, sometidos a profundos cambios y que están recibiendo diferentes iniciativas que tratan de paliar los efectos derivados de su desarticulación territorial y socioeconómica.

En base a estos argumentos, es preciso apuntar que el debate sobre el fenómeno neorrural cobró impulso en la Europa de los años ochenta, apoyado en las políticas de la Unión Europea cuyo objetivo básico residía en promover el desarrollo de las áreas rurales más atrasadas. Es así que a partir de los programas LEADER, comienza a desarrollarse en el ámbito académico la noción de neorruralidad para identificar las distintas actividades que se buscaba promover y que vinculaban el desarrollo socioeconómico con la sostenibilidad medioambiental.

De esta manera, se empieza a considerar al ámbito rural como un espacio multifuncional, donde la difusión de formas de vida urbanas, la movilidad de la población, los nuevos hábitos de consumo, los adelantos en las comunicaciones, etc. impregnan una nueva dinámica en la organización de este territorio.

Como se ha mencionado anteriormente, el enfoque de la nueva ruralidad ha dado cuenta de la necesidad de reconocer la multifuncionalidad de los ámbitos rurales y sus oportunidades para el desarrollo desde las diferentes dimensiones que se interrelacionan de forma transversal en el territorio (Calatrava Requena, 1999): la ambiental, económica, cultural, política, institucional y social, entre otras.

Dichos espacios intentan integrarse a esta nueva dinámica a través de nuevos procesos productivos entre los cuales se encuentra la aparición de actividades lucrativas vinculadas con usos no productivos del suelo agrícola como el turismo (González Fernández, 2002). En este orden de ideas, se ha visto el turismo rural como una actividad que presenta atrayentes potencialidades para el desarrollo rural el cual persigue objetivos económicos, sociales y medioambientales que, en la actualidad, no pueden ser alcanzados únicamente por medio de la actividad agraria siendo necesaria la ampliación de la actividad económica en estos espacios (Ivars Baidal, 1997).

Los factores que contribuyen a explicar este nuevo entorno son de diversa índole: los cambios de la demanda turística, el nuevo contexto económico y la creciente sensibilización política y social hacia los valores que atesora el mundo rural (González Fernández, 2002). 
Por tanto, el turismo, actividad que presenta un alto crecimiento en los últimos años, puede ser considerado como un instrumento de desarrollo territorial y un elemento clave en el proceso de terciarización de la economía puesto que diversifica la actividad agropecuaria al poner en valor otros recursos del campo como la naturaleza y la cultura del trabajo agrario. Como estrategia efectiva de desarrollo rural (Calatrava Requena, 1999), el turismo busca complementar, diversificar e incrementar las alternativas de empleo e ingresos de los pobladores rurales, los miembros de sus familias y, especialmente, de los jóvenes y las mujeres.

De este modo, las primeras ayudas comunitarias para el fomento del turismo en los espacios rurales aparecían inscritas en los objetivos de la intervención agraria y de política regional, y no estaban muy claros tampoco los modelos a seguir. Más tarde, con las actuaciones concretas de los programas LEADER, el enfoque cambió significativamente proponiendo una visión integrada del desarrollo rural con ayudas a la formación profesional, al empleo en las actividades agrícolas, a las pequeñas empresas de turismo en el medio rural, a la recuperación de los talleres de artesanía, a la mejora de los servicios locales y a la comercialización y ampliación del mercado de productos locales (Pardellas de Blas, 2000: 128-129).

De todo lo expuesto, se puede deducir que la actividad turística en el espacio rural permite hoy proponer cambios en el sistema productivo que impliquen una nueva dinámica de crecimiento. De todas formas, la recuperación y revitalización de la vida social y económica en los espacios rurales apoyada en las actividades turísticas exige una correcta integración en el sistema productivo local.

En este orden de ideas, para comprender la medida en la que el turismo contribuye al desarrollo integral y sostenible de las sociedades receptoras, se considera muy interesante la concepción sistémica-integradora aplicada al turismo que propone Álvarez Sousa (2005) al diferenciar siete capitales que es preciso tener en cuenta: capital social (que destaca el valor de las relaciones sociales y la cooperación y la confianza en la mejora de los resultados colectivos); capital simbólico (despliegue de signos y símbolos que conforman la imagen de un territorio); capital humano (formación y educación de los individuos), capital económico (los recursos financieros disponibles); capital infraestructural (construcciones y equipamientos diversos); capital patrimonial (recursos culturales) y capital ecológico (recursos naturales y medioambiente) los cuales no se dan de forma separada sino que existe entre ellos una relación en forma de red. Es, por tanto, necesario, ordenarlos de forma conjunta formando un sistema en el cual la integración ha de ser de modo horizontal, diagonal y vertical. No obstante, es preciso tener en cuenta que el desarrollo turístico debe de estar enfocado a la satisfacción de tres actores fundamentales que intervienen en el proceso: a) turistas, b) empresarios y c) ciudadanos de la sociedad receptora (Álvarez Sousa, 2005: 61-81).

El carácter turístico integrado cobra importancia como consecuencia de la complejidad y transversalidad que presenta la actividad turística la cual se refleja en la dialéctica tanto territorial como socio-económica y cultural de los diferentes espacios, donde cada área involucrada en esta dinámica opta por un determinado modelo 
de desarrollo, influyendo de manera importante las características que presentan los recursos territoriales y sociales básicos (López Olivares, 2003).

Además, el desarrollo turístico integrado debe contemplar como algo intrínseco a su conceptualización los siguientes aspectos (López Olivares, 2003: 112):

- La sostenibilidad de los recursos, junto a la viabilidad y rentabilidad económica social y medio ambiental a través de la cualificación productiva.

- El carácter endógeno del desarrollo integrado que también forma parte del desarrollo sostenible.

- Asumir el producto turístico como la suma de infraestructuras, servicios, empresas, tecnologías y recursos humanos superando una posible limitación de estrategias dirigidas exclusivamente a las tradicionales empresas turísticas, apostando por la transversalidad.

- Considerar el territorio más que como un simple soporte de la actividad, como configurador del producto final.

- Que los espacios no se caracterizan por tener un carácter cerrado sino que participan de un «sistema abierto» y en consecuencia está expuestos a las influencias externas lo que les hace estar en constante evolución.

- Que sea participativo, ya que el desarrollo turístico integrado requiere de la sociedad en general y, en particular, de los agentes tanto públicos como privados para alcanzar consensos que hagan posible alcanzar objetivos básicos en común que permita enfocar estrategias y programas de forma coordinada

\section{DIVERSIDAD DE TIPOLOGÍAS TURÍSTICAS QUE VERTEBRAN EL CA- MINO DE SANTIAGO. EL CAMINO FRANCÉS}

El Camino de Santiago conforma una ruta de peregrinación cuyos orígenes se remontan al siglo XI a raíz del descubrimiento, según la leyenda, de la tumba del Santo Apóstol Santiago el Mayor en Santiago de Compostela; desde entonces, se inaugura una ruta de intercambio cultural con el Norte de Europa que dura ya diez siglos. Este flujo continuado de individuos, aunque inspirado en motivos religiosos, puede considerarse una de las primeras rutas turísticas de la historia, contando con todos los elementos necesarios para ser observada como tal: "oferta de alojamiento" (albergue para peregrinos), "oferta complementaria", (posadas, mesones), "recursos turísticos” (monumentales, históricos, naturales...) (López Palomeque, 1993).

El Camino Francés es el Camino de Santiago con mayor tradición histórica y el más reconocido internacionalmente. El itinerario de esta ruta a través del norte de la Penísula Ibérica quedó fijado a fines del siglo XI, gracias a la labor constructiva y promocional de Sancho III el Mayor y Sancho Ramírez de Navarra y Aragón, así como de Alfonso VI y sus sucesores en Castilla, León y Galicia. Las principales vías de este itinerario en Francia y España fueron descritas hacia 1135 en el Libro V del "Codex Calixtinus", un texto fundamental del acervo jacobeo. 
El Camino Francés, partiendo de Saint Jean Pied de Port hasta Santiago de Compostela, es un viaje de casi 800 kilómetros hacia el oeste, es la gran ruta que enlaza Europa con el norte de España: Aragón, Navarra, Rioja, Castilla y Galicia

El Camino Francés de Santiago atraviesa Galicia siguiendo una dirección este-oeste y discurre por catorce municipios de las provincias de Lugo (Pedradita do Cebreiro, As Nogais, Triacastela, Samos, Sarria, O Páramo, Paradela, Portomarín, Guntín, Monterroso y Palas de Rei) y A Coruña (Melide, Arzúa y O Pino).

Hoy conviven en torno al escenario del Camino de Santiago, diversos tipos de peregrinaciones y de viajes; es decir, las peregrinaciones, además de su carácter religioso o espiritual, han adquirido un nuevo perfil hacia una orientación más bien laica y, principalmente, turística. El Camino, en definitiva, se concibe como un producto turístico más, como una faceta más del consumismo, aunque incorpora su singularidad y las connotaciones culturales y hasta religiosas ya conocidas.

Nos encontramos, de este modo, ante una tipología turística en la que se combinan los aspectos religioso, ecológico, cultural, social, deportivo y aventurero (Santos Solla, 1997). De este modo, el Camino de Santiago como fenómeno religioso y también como fenómeno social de carácter laico presenta los rasgos evidentes y propios de las manifestaciones turísticas.

A lo largo de su historia, el Camino ha pasado por avatares muy diversos pero será en la segunda mitad del siglo XIX cuando el fenómeno jacobeo adquiere de nuevo protagonismo. No fue hasta comienzos de los años 80 cuando se despertó el interés por el Camino de Santiago, es a partir de esta década cuando se destinan importantes partidas económicas desde las Administraciones Públicas y se impulsa una importante movilización de recursos simbólicos con el fin de conservar, restaurar y promocionar el Camino de Santiago.

Diversas son las claves de esta reanimación del itinerario compostelano aunque podría señalarse que el gran impulso comenzó con el Plan "Xacobeo '93" elaborado por la Xunta de Galicia con motivo de la celebración del Año Compostelano. Este Plan ha contado con el apoyo y la colaboración de varias instituciones gubernamentales y eclesiásticas y con la ayuda de empresas privadas.

De este modo, todas las regiones incluidas en el Camino de Santiago Francés reciben algún tipo de ayudas comunitarias en razón de su problemática específica destacando así la gran importancia del Camino como eje económico y cultural. Con este fin se pusieron en marcha una serie de planes de formación no reglada, destinada a numerosos colectivos, como los propietarios de las casas rurales, o a la formación de artesanos, incluyendo en un apartado específico el trabajo con mujeres (García Abril, 1999: 165).

En este sentido, la celebración de los Años Santos ha sido el pretexto para buscar una proyección nacional e internacional del país apoyado en un acontecimiento y en un territorio muy concreto, con un objetivo material inmediato: el despegue económico de Galicia en particular y de todo el Norte español en general (Marchena Gómez, 1993: 926). 
Es evidente que cuando el Consejo de Europa eligió, en 1987, el Camino de Santiago como proyecto piloto dentro de las actividades de promoción de los itinerarios culturales europeos, definiendo la Ruta Jacobea como "Primer Itinerario Cultural Europeo" apostaba por la revitalización de un acontecimiento secular de peregrinación; pero especialmente significaba el impulso a una nueva fórmula turística, menos estandarizada y mediatizada, en clara consonancia con las motivaciones cambiantes de la demanda. Por otro lado, en 1993 fue declarado por la UNESCO el conjunto español del Camino Francés, Patrimonio Mundial de la Humanidad. Posteriormente, el Año Santo Compostelano de 2004, ha recibido el galardón que lo distingue como Premio Príncipe de Asturias de la Concordia, considerado como reconocimiento y culminación de la recuperación de la ruta jacobea.

Todos estos factores suponen respaldos decisivos de promoción y comercialización internacional por lo que su rehabilitación y ordenación turística integrada sobrepasan el marco de las políticas sectoriales y regionales para enmarcarse en proyectos globales de desarrollo regional comunitario.

En la Figura ${ }^{\circ} 1$ se observa la evolución del número de peregrinos que recibieron la "compostela" entre 1991 y 2005. Prácticamente, se duplica el número de individuos que recorren la ruta de un Año Santo Compostelano a otro, de 1993 a 1999 con un incremento del $88,35 \%$ y, entre 1999 y 2004, asciende el porcentaje al 16,4 \%.

La celebración de los Años Santos tiene un efecto multiplicador en Santiago, obteniendo la cifra de $918,39 \%$ en 1993, respecto al año 1992. Es especialmente destacable el año 1999, pues en este jubileo acudieron a Compostela 154.613 peregrinos, un 55,49 \% más que en 1993, lo que supone 55177 más en el último año jacobeo que en el anterior de las mismas características y, como se puede apreciar, continúan las mismas tendencias en el Xacobeo 2004.

Figura ${ }^{\circ} 1$. Número de peregrinos a Santiago de Compostela (1991-2005)

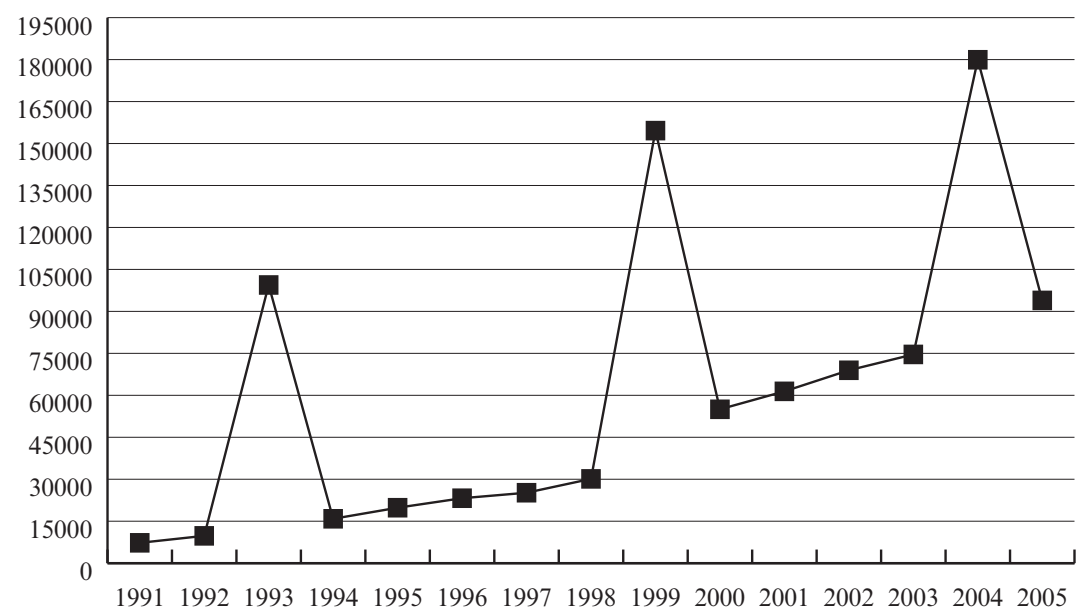

Fuente: Registro de la Oficina de Acogida de Peregrinos. Elaboración Oficina de Sociología del Arzobispado de Santiago de Compostela 


\section{DISEÑO METODOLÓGICO DE LA INVESTIGACIÓN}

El propósito de la presente investigación es estudiar las repercusiones o impactos del Camino de Santiago sobre el desarrollo de los espacios rurales que lo conforman con el fin de indagar si el la Ruta Jacobea supone un factor de influencia o solamente un hecho anecdótico en el desarrollo de estos municipios.

De esta manera, el objetivo general que persigue la investigación se orienta a evaluar la repercusión del Camino de Santiago en el desarrollo de los municipios por los que transcurre.

Este objetivo se descompone en los siguientes objetivos específicos:

- Estudiar la evolución y la dinámica de la población de los municipios del Camino de Santiago Francés con el fin de observar si esta ruta provoca una desaceleración del declive demográfico en estas localidades.

- Analizar si el Camino de Santiago ha llegado a ser una estrategia de revitalización de la economía de estos municipios rurales.

- Determinar la contribución del Camino de Santiago a la dinamización turística de estas localidades rurales.

La hipótesis inicial y más importante corresponde a insistir en lo siguiente: Las repercusiones del Camino de Santiago Francés sirven para relanzar el desarrollo social y económico de estos espacios rurales.

Se toman también como punto de partida una serie de hipótesis secundarias:

- El Camino de Santiago es un factor de influencia en el comportamiento demográfico de estas localidades consiguiendo ser un freno a la despoblación.

- El Camino de Santiago ha producido una progresiva recuperación económica (en base a la cuota de mercado y la actividad comercial) de estos municipios rurales.

- El Camino de Santiago ha favorecido el desarrollo turístico de los municipios camineros por los que transcurre.

El campo de actuación de este estudio está referido al Camino Francés el cual atraviesa Galicia siguiendo una dirección este-oeste y discurre por una serie de municipios de las provincias de Lugo y A Coruña. De hecho, esta exposición se basará en el análisis los cambios operados en los catorce municipios que se enumeran a continuación: Pedradita do Cebreiro, As Nogais, Triacastela, Samos, Sarria, O Páramo, Paradela, Portomarín, Guntín, Monterroso y Palas de Rei, en la provincia de Lugo; y Melide, Arzúa y O Pino, en la provincia de A Coruña.

Se realiza una evaluación y análisis del desarrollo que estos municipios han experimentado en el período comprendido entre 1991 y 2005, en el cual han tenido lugar tres Años Xacobeos (1993, 1999 y 2004). Se ha pretendido así contar con una percepción suficientemente amplia como para poder evaluar las posibles oscilaciones que hubiesen aparecido a lo largo de estos años en estas localidades.

Dicho análisis se lleva a cabo en base a los siguientes indicadores objetivos: el crecimiento demográfico, el índice turístico, la cuota de mercado y el número de 
licencias comerciales, todo ello con el fin de averiguar el grado de importancia del Camino de Santiago en el desarrollo de estas localidades. Para analizar estas repercusiones, se ha acudido a las bases de datos del Instituto Galego de Estadística y de la Fundación La Caixa (Anuario Social y Económico de España) y que en anteriores años era publicado por Banesto (Anuario del Mercado Español y Anuario Comercial de España). Por supuesto que existen otras dimensiones como la cultural, la social o la medioambiental pero, en el presente trabajo, se va a dejar en un segundo plano, lo cual no quiere decir que su importancia sea menor.

A su vez, para poder realizar un análisis con mayor precisión de la evolución de estas variables en las localidades mencionadas, se ha procedido a realizar esta labor desagregando los municipios rurales objeto de estudio por provincias y en base al número de habitantes, de modo que sirviera para establecer comparaciones más precisas y más correctas.

A la hora de considerar la denominación de "municipio rural", el número máximo de habitantes fluctúa en las distintas Comunidades Autónomas entre los 500 y 20.000 habitantes, si bien para el Instituto Nacional de Estadística son municipios rurales aquellos cuya población no excede de los 10.000 habitantes. Por tanto, en este estudio se ha elaborado la siguiente tipología de municipios en base a una clasificación de los mismos por su número de habitantes:

$1^{\circ}$ grupo: municipios de menos de 2.500 habitantes

$2^{\circ}$ grupo: municipios entre 2.500 y 4.999 habitantes

$3^{\circ}$ grupo: municipios entre 5.000 y 9.999 habitantes

$4^{\circ}$ grupo: municipios entre 10.000 y 19.999 habitantes

Bajo estas premisas, se exponen a continuación las variables utilizadas en el presente trabajo:

\section{Población}

Los cambios demográficos constituyen uno de los elementos clave en el análisis de la situación de cualquier área en tanto que reflejan una determinada dinámica socioeconómica. Se recoge esta variable entre los años 1991 y 2005 y se analizará asimismo en tres etapas: 1991 a 1996, 1996 a 2001 y 2001 a 2005 mediante los cálculos de la variación absoluta y en porcentaje de la población y la tasa de crecimiento medida en porcentaje.

\section{Cuota de mercado}

Índice que expresa la capacidad de consumo comparativa de los municipios y se elabora mediante un modelo equivalente a un promedio de números índices de las siguientes variables: población, número de teléfonos, automóviles, camiones, oficinas bancarias y actividades comerciales minoristas. Se estudiará la evolución y el estado de esta variable ${ }^{2}$ para los años 1991, 1996, 1999, 2001 y 2004 y en base a tres

2 Sólo existe información a nivel municipal para esta variable y para la variable "actividad comercial" en los municipios con población superior a 1.000 habitantes, en este sentido, queda fuera del análisis el municipio de Triacastela, puesto que sólo supera esa cifra de habitantes en el año 1991. 
períodos: de 1991 a 1996, de 1996 a 2001 y de 2001 a 2004 con el fin de evaluar si el Camino constituye una fuente de revitalización de la economía de estos municipios.

Por otro lado, al igual que con la variable de población, se realizará el desglose de los municipios por provincias y en base al número de habitantes.

\section{Actividad comercial}

El grado de innovación y modernización de un núcleo de población puede analizarse a través del comercio ya que de las características de éste puede derivarse el dinamismo de un municipio. De este modo, se considera que es un indicador útil que sirve para reflejar la repercusión del Camino de Santiago en estos municipios.

Se recopila esta variable para 1991, 1996, 1999, 2001 y 2004 y se estudia su evolución a través del porcentaje de crecimiento en base a tres períodos: de 1991 a 1996, de 1996 a 2001 y de 2001 a 2004. Al igual que con las demás variables, se realizará el desglose de los municipios por provincias y en base al número de habitantes.

Por otra parte, la variable referida al número de licencias comerciales ha supuesto tener que agrupar las actividades comerciales mayoristas ${ }^{3}$, minoristas $^{4}$ y las actividades industriales ${ }^{5}$, puesto que las categorías existentes diferían de unos años a otros y hacerlo de este modo era la única forma de obtener una variable que permitiese contemplar una evolución temporal sin introducir sesgos relevantes.

\section{Índice turístico}

Índice comparativo de la importancia turística que se obtiene en función de la cuota o impuesto de actividades económicas correspondiente a las turísticas el cual se basa, a su vez, en la categoría de los establecimientos turísticos (hoteles y moteles, hoteles-apartamentos, hostales y pensiones, fondas y casas de huéspedes, campings y apartamentos gestionados por empresas), número de habitaciones y ocupación anual. Es más bien un indicador de la importancia de la oferta turística y no de la demanda turística (pernoctaciones).

El valor del índice indica la participación (en tanto por 100.000) que corresponde a cada municipio sobre una base nacional de 100.000 unidades (total euros

\footnotetext{
3 Actividades comerciales mayoristas: Número de actividades del comercio mayorista, derivadas del impuesto de actividades económicas (IAE), que constituyen una buena aproximación del número de establecimientos comerciales mayoristas existentes en cada municipio y es elaborada con la información facilitada por el Ministerio de Hacienda.

4 Actividades comerciales minoristas: Número de actividades del comercio detallista sujetas al impuesto de actividades económicas (IAE). Dichas actividades se identifican con las que la Clasificación Nacional de Actividades Económicas (CNAE) del INE considera comercio al por menor. Contiene información desglosada de las actividades comerciales minoristas en tres grupos: alimentación (que comprende tanto el pequeño comercio tradicional como los supermercados); no alimentación (comercio tradicional); y comercio mixto y otros.

5 Actividades industriales: Número de actividades industriales, las cuales están sujetas al impuesto de actividades económicas (IAE). El número de actividades industriales equivale prácticamente al número de establecimientos industriales existentes en cada municipio y se desglosan en actividades industriales propiamente dichas y construcción.
} 
recaudación impuesto $(\mathrm{IAE})=100.000)$. Este índice ${ }^{6}$ es elaborado a partir de la información facilitada por el Ministerio de Hacienda y se calcula en función de la cuota tributaria (cuota de tarifa) del impuesto de actividades económicas (IAE), que tiene en cuenta el número de habitaciones, así como la ocupación anual (apertura durante parte o todo el año) y categoría de los establecimientos turísticos. Las estimaciones se refieren a 2003.

Se recopila esta variable para los años 1991, 1996, 1999, 2003 y se ha estudiado también su evolución utilizando el cálculo del porcentaje de variación o crecimiento en base a tres períodos de análisis: de 1991 a 1996, de 1996 a 1999 y de 1999 a 2004 y, al igual que con las demás variables objetote análisis, se realizará el desglose de los municipios por provincias y en base al número de habitantes.

\section{ANÁLISIS DE RESULTADOS}

\section{V.1. ANÁLISIS DE LA DINÁMICA DEMOGRÁFICA}

Con el propósito de verificar si el Camino de Santiago es un factor de influencia en el comportamiento demográfico de los municipios rurales por los que transcurre, se ha procedido a la realización de análisis que se presentan a continuación

6 Puesto que la fuente secundaria utilizada sólo publica información a nivel municipal para los municipios españoles con población superior a 1.000 habitantes, queda fuera del análisis el municipio de Triacastela, puesto que sólo supera esa cifra de habitantes en el año 1991, y por otro lado, debido a que este índice sólo se elabora para los municipios que poseen un mínimo de 50 plazas hoteleras, han quedado fuera del análisis algunos municipios que no cumplen este requisito, sobre todo para el primer año de análisis, 1991. 
Tabla $n^{\circ}$ 1. Evolución de la población de los municipios del Camino de Santiago Francés (1991 - 2005)

\begin{tabular}{|l|c|c|}
\hline \multirow{2}{*}{ Municipios del Camino de Santiago } & \multicolumn{2}{|c|}{ Población 1.991-2.005 } \\
\cline { 2 - 3 } & Variación absoluta & Variación en \% \\
\hline Arzúa & -414 & $-5,90$ \\
\hline Melide & -438 & $-5,27$ \\
\hline Pino, O & -380 & $-7,20$ \\
\hline Guntín & -698 & $-17,43$ \\
\hline Monterroso & -368 & $-8,04$ \\
\hline Nogais, As & -479 & $-24,49$ \\
\hline Palas de Rei & -1.192 & $-23,76$ \\
\hline Paradela & -859 & $-26,63$ \\
\hline Páramo, O & -248 & $-11,78$ \\
\hline Pedrafita do Cebreiro & -688 & $-32,09$ \\
\hline Portomarín & -319 & $-14,26$ \\
\hline Samos & -516 & $-21,38$ \\
\hline Sarria & 544 & 4,31 \\
\hline Triacastela & -248 & $-23,22$ \\
\hline
\end{tabular}

Fuente: I.G.E. Censos de población. Padrón municipal de habitantes 
Figura ${ }^{\circ} 2$. Tasas de crecimiento de la población de los municipios del Camino de Santiago Francés (1991 - 2005)

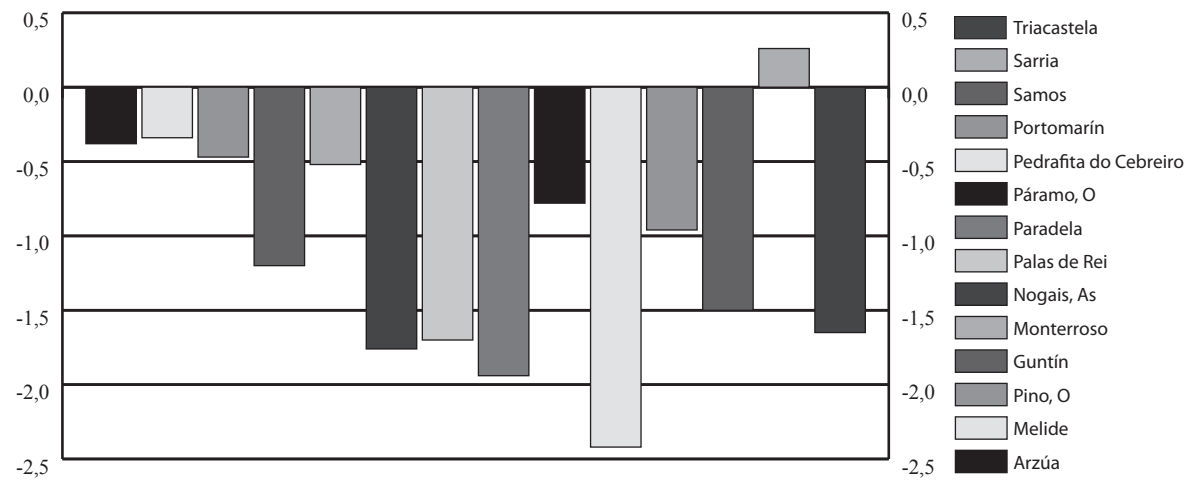

Fuente: I.G.E. Censos de población. Padrón municipal de habitantes

Se aprecia en la Tabla ${ }^{\circ} 1$ que Sarria es el único municipio que gana población entre 1.991 y 2.005 , los restantes núcleos rurales sufren a lo largo de este período una tendencia demográfica regresiva, siendo Pedrafita y Paradela los que poseen mayor porcentaje de pérdida de población. Entre 1991 y 1996, únicamente incrementan la población Melide y Sarria. Entre 1996 y 2001, las tendencias empeoran en todos los municipios, siendo Sarria el único con una leve variación positiva, lo mismo que sucede entre 2001 y 2005.

En la Figura $n^{\circ} 2$ se pone de manifiesto que las tasas de crecimiento (1991 a 2005) son negativas, sobre todo en el caso de Pedrafita. El único municipio que obtiene una tasa positiva es Sarria; entre 1991 y 1996 son Melide y Sarria los únicos que crecen. No obstante, entre 1996 y 2001 Sarria continúa creciendo ligeramente pero Melide y Arzúa no logran seguir aumentando su número de habitantes. Entre 2001 y 2005 las tasas empeoran para el conjunto de municipios analizados. 
Figura $\mathrm{n}^{\circ} 3$. Tasas de crecimiento de población de los municipios del Camino de Santiago Francés por provincias (1991 - 2005)

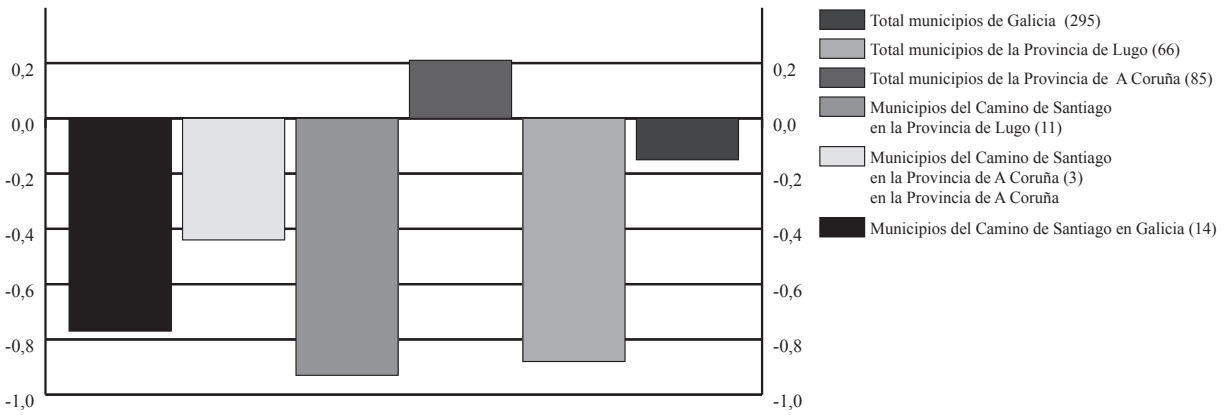

Fuente: I.G.E. Censos de población. Padrón municipal de habitantes

Los municipios jacobeos (Figura $n^{\circ} 3$ ) muestran una tasa de crecimiento de 1991 a 2005 peor que la media de la comunidad gallega. Los municipios camineros coruñeses tienen una tasa muy inferior a la media de su provincia aunque, sin embargo, mejor que la de los municipios camineros lucenses. La tasa de crecimiento de estos municipios entre 1991 a 1996 es de $-0,57 \%$, ligeramente por debajo de la gallega. La media de los municipios camineros coruñeses es positiva al igual que la de su provincia.

También los municipios lucenses poseen una tasa mejor que la de su provincia. Entre 1996 y 2001, la media de esta tasa para los municipios camineros sigue por debajo de la gallega y entre 2001 y 2005, sus tasas siguen empeorando.

La Tabla $\mathrm{n}^{\circ} 2$ permite observar que la tasa media de crecimiento (1991-2005) en los municipios camineros menores de 2500 hab. (-2,60\%) es peor que la gallega $(-1,63$ $\%$ ) y la provincial (-1,77\%). Por etapas, comprobamos que entre 1991 a 1996 la media de estas localidades es algo mejor (-1,98\%) que la gallega $(-2,09 \%)$ y la lucense $(-2,26$ \%) pero esta tendencia se rompe a partir de 1996 a 2001. 
Tabla $\mathrm{n}^{\mathrm{o}} 2$. Tasas de crecimiento de la población de los municipios del Camino de Santiago Francés menores de 2.500 h. (1991 - 2005)

\begin{tabular}{|l|c|}
\hline $\begin{array}{l}\text { Municipios del Camino de Santiago de } \\
\text { menos de 2.500 hab }\end{array}$ & $\begin{array}{c}\text { Población } \\
1991-2005\end{array}$ \\
\hline Nogais, As (Lugo) & $-2,76$ \\
\hline Paradela (Lugo) & $-2,55$ \\
\hline Páramo, O (Lugo) & $-1,33$ \\
\hline Pedrafita do Cebreiro (Lugo) & $-3,64$ \\
\hline Portomarín (Lugo) & $-1,82$ \\
\hline Samos (Lugo) & $-3,54$ \\
\hline Triacastela (Lugo) & $-2,58$ \\
\hline $\begin{array}{l}\text { Total municipios del Camino de Santiago } \\
\text { de menos de 2.500 hab. }\end{array}$ & $-2,60$ \\
\hline $\begin{array}{l}\text { Total municipios de Lugo de } \\
\text { menos de 2.500 hab (29) }\end{array}$ & $-1,77$ \\
\hline $\begin{array}{l}\text { Total municipios de Galicia de } \\
\text { menos de 2.500 hab (117) }\end{array}$ & $-1,63$ \\
\hline
\end{tabular}

Fuente: I.G.E. Censos de población. Padrón municipal de habitantes

En la Tabla $n^{\circ} 3$ se aprecia que los municipios camineros entre 2.500 y 4.999 hab. poseen una tasa de crecimiento entre 1991 y 2005 peor que la gallega. Si la analizamos en tres periodos, entre 1991 y 1996 ésta es prácticamente igual a la gallega.

Además, la tasa de crecimiento de los municipios camineros de Lugo es mejor que la media lucense aunque $\mathrm{O}$ Pino posee una tasa peor que la media coruñesa. Entre 1996 y 2001 la tasa de crecimiento de estos municipios empeora y también entre 2001 y 2005. 
Tabla $n^{\circ}$ 3. Tasas de crecimiento de la población de los municipios del Camino de Santiago Francés entre 2.500 y 4.999 h. (1991-2005)

\begin{tabular}{lc} 
Municipios del Camino de Santiago entre & Población \\
2.500 y 4.999 hab. & $1991-2005$ \\
\hline Pino, O (A Coruña) & $-0,53$ \\
Guntín (Lugo) & $-1,36$ \\
Monterroso (Lugo) & $-0,59$ \\
Palas de Rei (Lugo) & $-1,93$ \\
Total municipios del Camino de Santiago entre 2.500 y 4.999 hab. & $-1,07$ \\
(A Coruña) & $-1,29$ \\
Total municipios del Camino de Santiago entre 2.500 y 4.999 hab (Lugo) & \\
Total municipios de A Coruña entre 2.500 y 4.999 hab (20) & $-0,38$ \\
Total municipios de Lugo entre 2.500 y 4.999 hab (25) & $-1,76$ \\
Total municipios de Galicia entre 2.500 y 4.999 hab (80) & $-0,87$
\end{tabular}

Fuente: I.G.E. Censos de población. Padrón municipal de habitantes

Tabla $\mathrm{n}^{\mathrm{o}}$ 4. Tasas de crecimiento de la población de los municipios del Camino de Santiago Francés entre 5.000 y 9.999 h. (1991 - 2005)

\begin{tabular}{lc}
$\begin{array}{l}\text { Municipios del Camino de Santiago } \\
\text { entre } 5.000 \text { y } 9.999 \text { hab (A Coruña) }\end{array}$ & $\begin{array}{c}\text { Población } \\
1991-2005\end{array}$ \\
\hline Arzúa (A Coruña) & $-0,43$ \\
Melide (A Coruña) & $-0,38$ \\
$\begin{array}{l}\text { Total municipios del Camino } \\
\text { entre 5.000 y 9.999 hab }\end{array}$ & $-0,40$ \\
$\begin{array}{l}\text { Total municipios de A Coruña } \\
\text { entre 5.000 y 9.999 hab (33) }\end{array}$ & $-0,07$ \\
$\begin{array}{l}\text { Total municipios de Galicia } \\
\text { entre 5.000y } 9.999 \text { hab (61) }\end{array}$ & $-0,005$
\end{tabular}

Fuente: I.G.E. Censos de población. Padrón municipal de habitantes

Por otra parte, el municipio de Sarria, el único del Camino que posee entre 10.000 y 19.999 habitantes, manifiesta en el periodo comprendido entre 1991 y 2005 una tasa de crecimiento positiva $(0,30 \%)$ y mejor que la media de la provincia a la que pertenece, Lugo: $-0,06 \%$, aunque no tan buena como la gallega $(0,76 \%)$. Pero esta tendencia se va desdibujando con los años y sus cifras van empeorando. 
En definitiva, se comprueba el desastre demográfico registrado en la mayoría de núcleos rurales camineros. Todos pierden un volumen significativo de población desde 1991, y solo la presencia de una cabecera comarcal terciarizada (Sarria), permite moderar esta tendencia; incluso Arzúa o Melide, o bien pierden población o muestran crecimientos pequeños. Lo mismo ocurre en Monterroso, beneficiado de la instalación de pequeñas industrias y de un centro penitenciario y en $\mathrm{O}$ Pino, en el que la cercanía a Compostela quizás justifica la menor regresividad demográfica. Se registra, además, una fuerte disminución de población en los municipios camineros menores de 2.500 habitantes pertenecientes a Lugo aunque es en este grupo donde se atisba desde 2.001 una leve mejora. Así, parece que el Camino no consigue superar la crisis en lo demográfico puesto que, en un principio, no contribuye a evitar la pérdida poblacional.

A la vista de los resultados, podemos afirmar que el efecto del Camino no ha sido suficiente para invertir la tendencia decreciente de la población de los lugares por donde pasa, que continúan el proceso de despoblamiento.

Cabe, sin embargo, destacar el efecto concentrador del crecimiento a escala local de las cabeceras de comarca y sobre todo de la propia ciudad de Santiago pero, en ambos casos, los impulsos están más directamente relacionados con el efecto de otros procesos de desarrollo territorial (Precedo, 2004:153).

\section{V.2. ANÁLISIS DE LA CUOTA DE MERCADO}

A continuación, con el objetivo de verificar si el Camino de Santiago ha producido una progresiva recuperación económica del conjunto de municipios rurales examinados, se prestará atención a la variable cuota de mercado. 
Tabla $n^{\circ}$ 5. Distribución de la cuota de mercado en los municipios del Camino de Santiago (1991-2004)

$\begin{array}{lccccc}\begin{array}{l}\text { Municipios del Camino de } \\ \text { Santiago }\end{array} & \begin{array}{c}\text { Cuota } \\ \text { Mercado } \\ 1991\end{array} & \begin{array}{c}\text { Cuota } \\ \text { Mercado } \\ 1996\end{array} & \begin{array}{c}\text { Cuota } \\ \text { Mercado } \\ 1999\end{array} & \begin{array}{c}\text { Cuota } \\ \text { Mercado } \\ 2001\end{array} & \begin{array}{c}\text { Cuota } \\ \text { Mercado } \\ 2004\end{array} \\ \text { Arzúa } & 15 & 17 & 17 & 16 & 16 \\ \text { Melide } & 18 & 21 & 21 & 19 & 19 \\ \text { Pino, O } & 7 & 10 & 10 & 10 & 10 \\ \text { Guntín } & 5 & 8 & 7 & 7 & 7 \\ \text { Monterroso } & 9 & 10 & 10 & 9 & 10 \\ \text { Nogais, As } & 3 & 4 & 4 & 4 & 3 \\ \text { Palas de Rei } & 11 & 11 & 10 & 10 & 9 \\ \text { Paradela } & 6 & 6 & 6 & 6 & 5 \\ \text { Páramo, O } & 2 & 4 & 4 & 4 & 4 \\ \text { Pedrafita do Cebreiro } & 5 & 5 & 4 & 4 & 4 \\ \text { Portomarín } & 4 & 5 & 5 & 5 & 4 \\ \text { Samos } & 3 & 5 & 4 & 5 & 4 \\ \text { Sarria } & 34 & 34 & 34 & 33 & 32 \\ \text { Triacastela } & 2 & - & - & - & -\end{array}$

Fuentes: Anuario del Mercado Español Banesto, 1992; Anuario Comercial de España, 1998; Anuario Económico de España, 2001, 2002, 2005 
Figura $\mathrm{n}^{\circ}$ 4. Crecimiento de la cuota de mercado en los municipios del Camino de Santiago Francés (1991 - 2004)

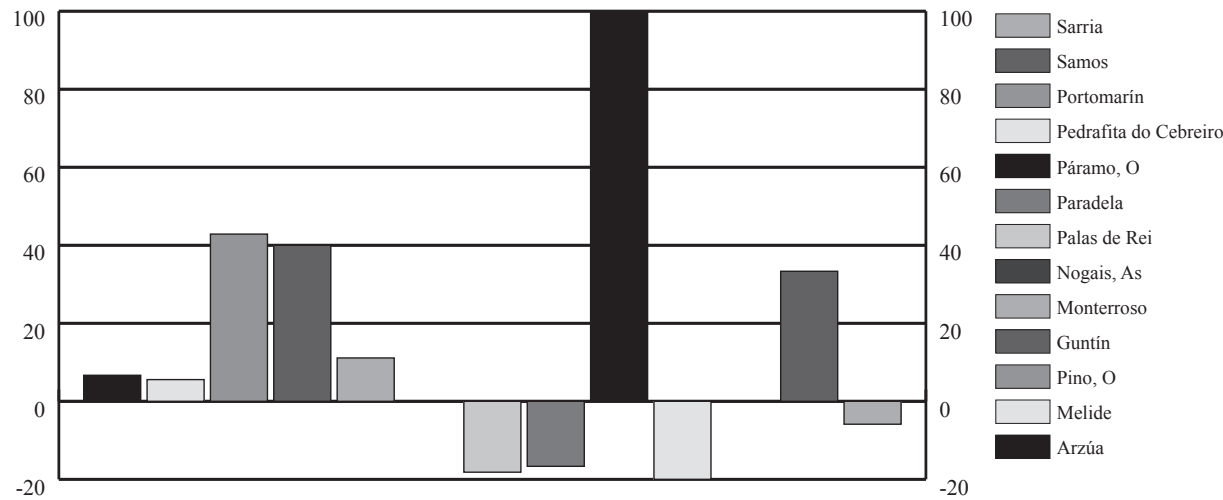

Fuentes: Anuario del Mercado Español Banesto, 1992; Anuario Comercial de España, 1998; Anuario Económico de España, 2001, 2002, 2005

En la Figura $n^{\circ} 4$, se aprecia que el mayor porcentaje de crecimiento de cuota de mercado para los municipios camineros en el periodo que abarca desde 1991 a 2004 es para O Páramo (con una variación del 100\%). Por otra parte, de los catorce municipios del Camino (si excluimos a Triacastela), se distinguen cuatro cuya cuota de mercado ha descendido en este periodo: Pedrafita do Cebreiro (-20\%), Palas de Rei (-18\%), Paradela (17\%) y Sarria (-6\%).

Desde 1991 a 1996, el porcentaje de crecimiento de la cuota de mercado para los municipios camineros es positivo, destacando O Páramo por ser el que más crece, sin embargo, de 1996 a 2001, ninguno de los citados municipios muestra ya un porcentaje de crecimiento favorable y, finalmente, entre 2001 y 2004, la tendencia es similar aunque tiende a empeorar para la mayor parte de los municipios.

Figura $\mathrm{n}^{\circ}$ 5. Crecimiento de la cuota de mercado en los municipios del Camino de Santiago Francés (1991 - 2004)

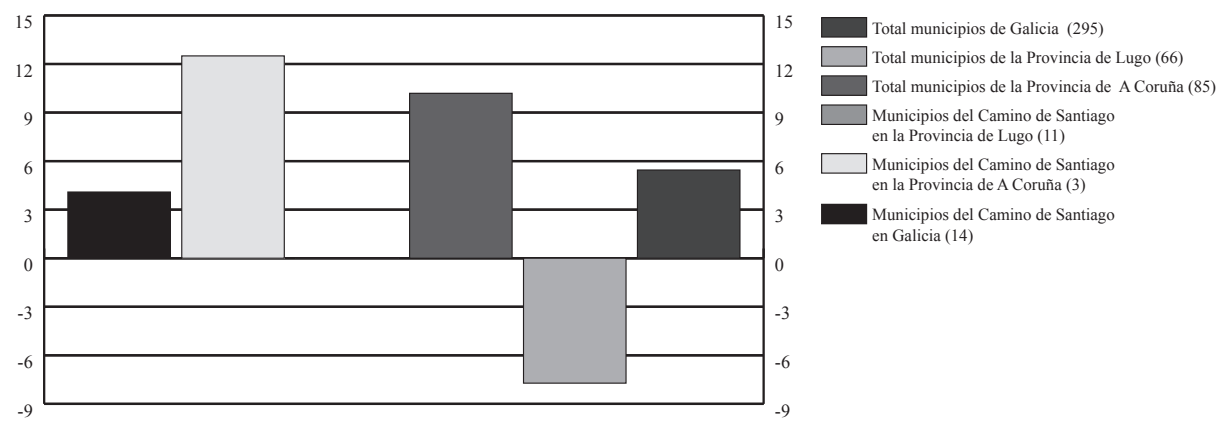

Fuentes: Anuario del Mercado Español Banesto, 1992; Anuario Comercial de España, 1998; Anuario Económico de España, 2001, 2002, 2005 
En la Figura ${ }^{\circ} 5$ se pone de manifiesto que el porcentaje de crecimiento de la cuota de mercado para los municipios jacobeos en el periodo comprendido entre 1991 a 2004 es menor que la media gallega aunque los municipios camineros coruñeses muestran un porcentaje mejor que los de su provincia y lo mismo sucede en los lucenses. Si realizamos el análisis en tres etapas, se puede observar que entre 1991 y 1996, el porcentaje de crecimiento para los municipios jacobeos es mayor que la media gallega, otro tanto ocurre para los municipios camineros coruñeses y, sobre todo, para los lucenses. Pero esta tendencia se rompe entre 1996 y 2001 siendo el porcentaje de crecimiento de esta variable negativo para los municipios jacobeos y peor que la media gallega, siendo la excepción los municipios camineros de Lugo. En la última etapa, los porcentajes de los municipios jacobeos son peores tanto comparados con la media gallega y como con la de sus respectivas provincias.

La Figura $n^{\circ} 6$ indica que, desde 1991 a 2004, el porcentaje de crecimiento de esta variable en los municipios jacobeos menores de 2.500 habitantes es mejor que la media gallega y la lucense. Si analizamos este crecimiento por etapas, de 1991 a 1996, la evolución de esta variable en los municipios camineros es muy buena comparada tanto con la media regional como con la provincial. No obstante, de 1996 a 2001, el crecimiento de la cuota de mercado de los municipios del Camino es negativo aunque ligeramente mejor que la media gallega y la de Lugo, finalmente, entre 2001 y 2004 la tendencia es de empeoramiento.

Figura $\mathrm{n}^{\mathrm{0}}$ 6. Crecimiento de la cuota de mercado en los municipios del Camino de Santiago Francés menores de 2.500 hab. (1991 -2004)
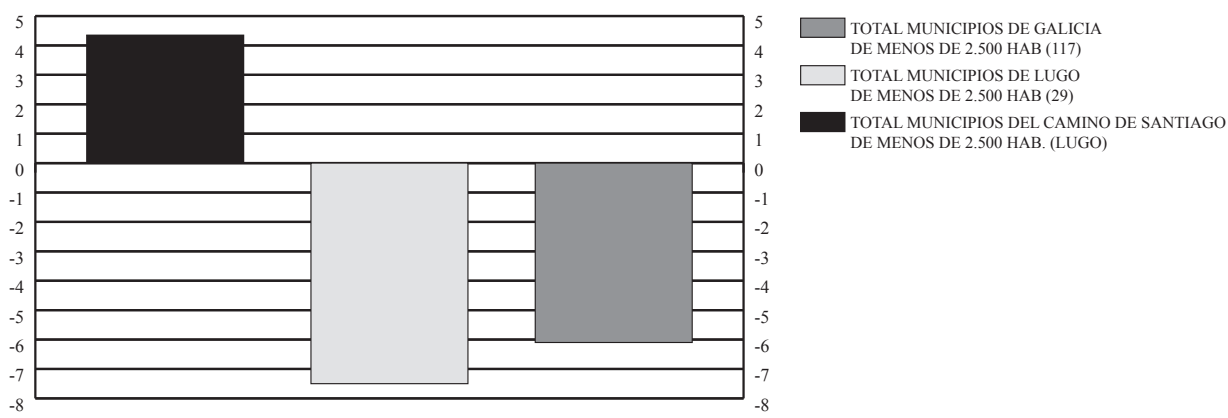

Fuentes: Anuario del Mercado Español Banesto, 1992; Anuario Comercial de España, 1998; Anuario Económico de España, 2001, 2002, 2005

Como se puede apreciar en la Figura $n^{0} 7$, el porcentaje de crecimiento de la cuota de mercado para el periodo comprendido entre 1991 a 2005 en los municipios jacobeos entre 2500 y 4999 habitantes es bastante mejor que la media gallega. De 1991 a 1996, el porcentaje de crecimiento de la citada variable para los municipios jacobeos de este grupo es casi tan buena como la media gallega aunque, desde 1996 hasta 2001, esta tendencia se invierte y los municipios por los que transcurre la Ruta Francesa poseen un porcentaje de crecimiento negativo y, además, peor que la me- 
dia gallega. En la última etapa, la cuota de mercado de los municipios del Camino apenas varía.

Figura $\mathrm{n}^{\circ} 7$. Crecimiento de la cuota de mercado de los municipios del Camino de Santiago Francés entre 2.500 y 4.999 h. (1991 - 2004)

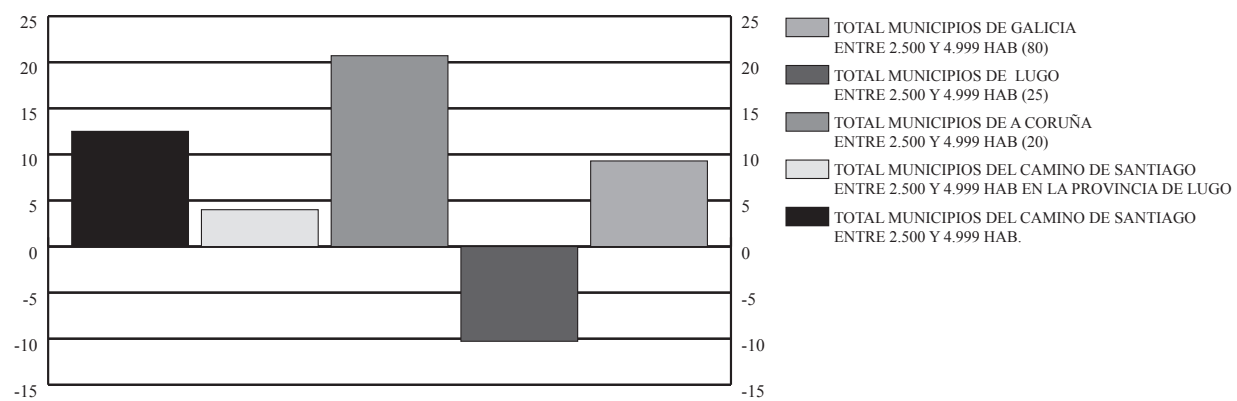

Fuentes: Anuario del Mercado Español Banesto, 1992; Anuario Comercial de España, 1998; Anuario Económico de España, 2001, 2002, 2005

Figura $\mathrm{n}^{\circ}$ 8. Crecimiento de la cuota de mercado de los municipios del Camino de Santiago Francés entre 5.000 y 9.999 hab. (1991-2004)

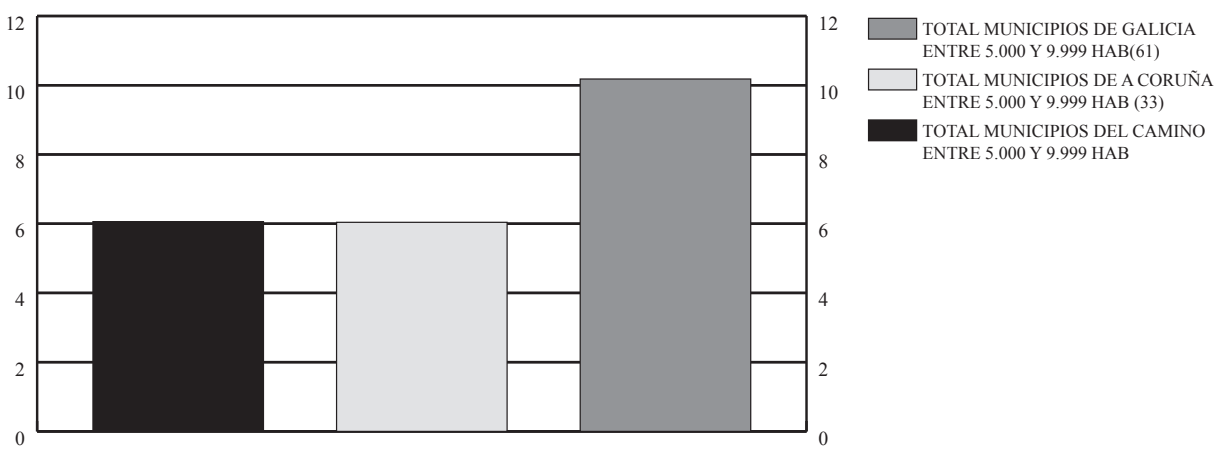

Fuentes: Anuario del Mercado Español Banesto, 1992; Anuario Comercial de España, 1998; Anuario Económico de España, 2001, 2002, 2005

Observamos en la Figura $n^{\circ} 8$ que los municipios del Camino entre 5.000 y 9.999 habitantes, es decir, Arzúa y Melide, poseen entre 1991 y 2004 un porcentaje de variación de la cuota de mercado similar al de su provincia aunque no tan bueno como la media gallega; entre 1991-1996, el porcentaje de crecimiento en estos municipios camineros es prácticamente similar que el de Galicia y mejor que el de su provincia, no obstante, esta tendencia se interrumpe entre 1996 y 2001, en la que tanto para Galicia como para Lugo empeora el porcentaje de crecimiento. De todos modos, se pone de manifiesto que entre 2001 y 2004 se da una ligera mejoría. 
Para el municipio de Sarria (municipio entre 10.000 y 19.999 habitantes), durante el periodo que abarca desde 1991 hasta 2004, la variación de la cuota de mercado se sitúa en el $-5,88 \%$, cifra que, siendo bastante peor que la de Galicia es, sin embargo, ligeramente superior a la de su provincia (Lugo). Por otra parte, este municipio experimenta la misma tendencia que los municipios camineros anteriormente analizados puesto que durante la etapa 1991 a 1996 da muestras de una evolución bastante aceptable, aunque empieza a empeorar estrepitosamente a partir del periodo 1996-2001 y continúa, o incluso empeora, en el intervalo de tiempo más reciente (2001-2004).

En definitiva, una vez realizado el análisis de la evolución de la cuota de mercado en los municipios del Camino de Santiago Francés, se pone de manifiesto que desde 1991 a 2004 evoluciona de manera similar a la del resto de localidades gallegas; entre 1991-1996, se produce una época de importante crecimiento pero esta tendencia cambia de signo entre 1996 y 2001 y sigue empeorando entre 2001-2004 para la mayoría de municipios camineros. Por tanto, parece ser que el Camino no constituye una fuente demasiado importante en la revitalización de la economía de estos municipios puesto que no están respondiendo de forma demasiado favorable a los impulsos de los planes Xacobeos en lo que se refiere a una progresiva recuperación económica.

\section{V.3. ANÁLISIS DE LA EVOLUCIÓN DE LA ACTIVIDAD COMERCIAL}

La evolución del porcentaje de crecimiento del número de licencias comerciales para los municipios del Camino entre 1991-2004 (Figura $n^{\circ} 11$ ) muestra una tendencia favorable siendo la localidad que más sobresale la de O Páramo. Entre 1991 y 1996 presentan todos los municipios camineros una evolución positiva, sin embargo, entre 1996 y 2001 las tendencias empeoran y lo mismo continúa sucediendo en el periodo que abarca de 2001 a 2004. 
Tabla $n^{\circ} 6$. Distribución de licencias comerciales en los municipios del Camino de Santiago Francés (1991- 2004)

\begin{tabular}{|c|c|c|c|c|c|}
\hline & $\begin{array}{c}\text { Licencias } \\
\text { comerciales } \\
1991\end{array}$ & $\begin{array}{c}\text { Licencias } \\
\text { comerciales } \\
1996\end{array}$ & $\begin{array}{c}\text { Licencias } \\
\text { comerciales } \\
1999\end{array}$ & $\begin{array}{c}\text { Licencias } \\
\text { comerciales } \\
2001\end{array}$ & $\begin{array}{c}\text { Licencias } \\
\text { comerciales } \\
2004\end{array}$ \\
\hline Arzúa & 190 & 308 & 314 & 330 & 324 \\
\hline Melide & 277 & 480 & 501 & 528 & 569 \\
\hline Pino, $\mathrm{O}$ & 93 & 154 & 167 & 174 & 190 \\
\hline Guntín & 55 & 65 & 73 & 80 & 89 \\
\hline Monterroso & 99 & 207 & 214 & 227 & 254 \\
\hline Nogais, As & 21 & 46 & 48 & 51 & 45 \\
\hline Palas de Rei & 117 & 125 & 135 & 148 & 146 \\
\hline Paradela & 47 & 76 & 79 & 90 & 93 \\
\hline Páramo, O & 14 & 50 & 47 & 57 & 59 \\
\hline Pedrafita do Cebreiro & 25 & 45 & 49 & 50 & 44 \\
\hline Portomarín & 31 & 74 & 77 & 88 & 91 \\
\hline Samos & 26 & 57 & 56 & 58 & 60 \\
\hline Sarria & 428 & 682 & 728 & 763 & 800 \\
\hline Triacastela & 6 & & & & \\
\hline
\end{tabular}

Fuentes: Anuario del Mercado Español Banesto, 1992; Anuario Comercial de España, 1998; Anuario Económico de España, 2001, 2002, 2005 
Figura $n^{\circ}$ 9. Crecimiento de licencias comerciales en los municipios del Camino de Santiago Francés (1991 a 2004)

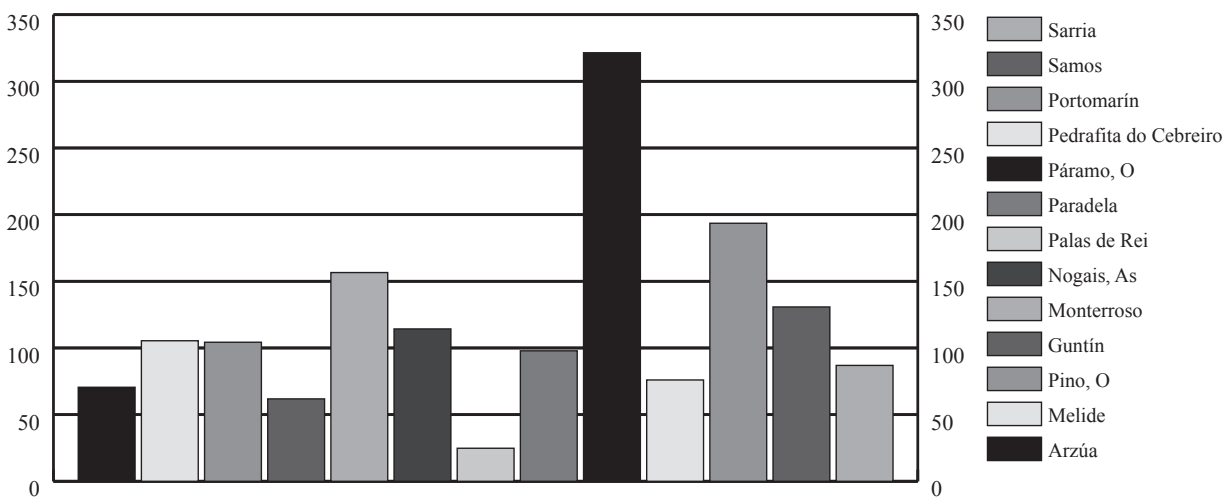

Fuentes: Anuario del Mercado Español Banesto, 1992; Anuario Comercial de España, 1998; Anuario Económico de España, 2001, 2002, 2005

Figura $\mathrm{n}^{\circ} 10$. Crecimiento de licencias comerciales en los municipios del Camino de Santiago Francés y por provincias (1991 -2004)

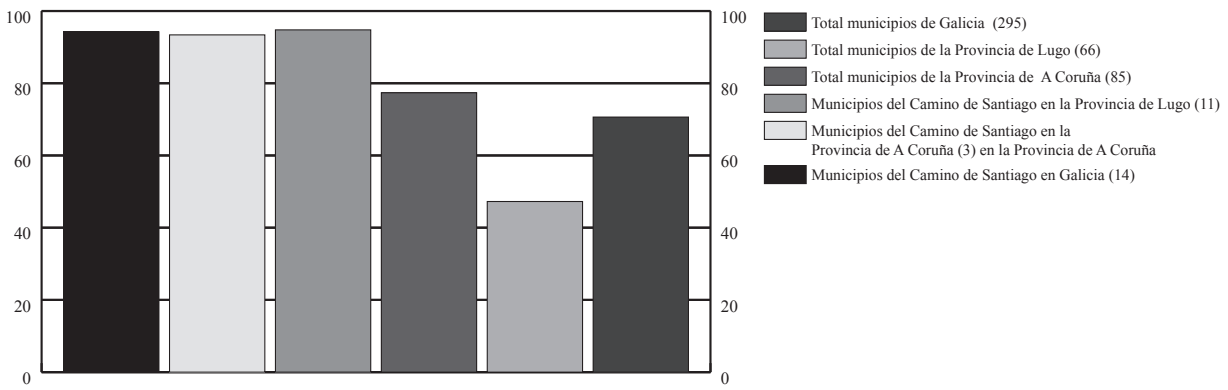

Fuentes: Anuario del Mercado Español Banesto, 1992; Anuario Comercial de España, 1998; Anuario Económico de España, 2001, 2002, 2005

En la Figura $n^{\circ} 10$, se puede observar que la evolución del porcentaje de crecimiento del número de licencias comerciales para los municipios del Camino es ligeramente superior a la media de los municipios gallegos. En este sentido, los municipios jacobeos de A Coruña muestran un porcentaje de crecimiento superior a la media coruñesa y, por otro lado, los municipios camineros de Lugo ponen de manifiesto un porcentaje de crecimiento de esta variable que casi duplica el de su provincia.

Entre 1991-1996, son los municipios jacobeos los que presentan un porcentaje de crecimiento de la actividad comercial superior a la media gallega y a la de sus respectivas provincias. Entre 1996-2001, esta tendencia empieza a dar signos de empeoramiento para confirmarse la ruptura entre 2001-2004 siendo, a partir de este momento, el porcentaje de crecimiento de los municipios camineros inferior al de Galicia y al de sus respectivas provincias. 
En la Figura $n^{\circ} 11$ se aprecia la evolución del crecimiento del número de licencias comerciales de los municipios del Camino que no superan los 2.500 habitabtes y que corresponde al $139 \%$, prácticamente el doble que la cifra de Galicia $(79,4 \%)$ y también, bastante mejor que la de Lugo (69,37\%). Si observamos la evolución del porcentaje de crecimiento de esta variable en estos los municipios diferenciando tres periodos, comprobamos que desde 1991 a 1996, el porcentaje de crecimiento de las licencias comerciales en estos núcleos es aproximadamente del $113 \%$, muy superior al alcanzado por los municipios gallegos en conjunto $(65 \%)$ y también al de los lucenses (56 \%). Entre 1996 y 2001, se hace patente el gran descenso en el porcentaje de variación de la actividad comercial que sufren estos municipios jacobeos y, desde 2.001 a 2.004, la tendencia que se venía manifestando en la etapa anterior se confirma, obteniendo estos municipios jacobeos un porcentaje de crecimiento de las licencias comerciales claramente negativo.

Figura $\mathrm{n}^{\circ}$ 11. Crecimiento de licencias comerciales en los municipios del Camino de Santiago Francés menores de 2.500 hab. (1991- 2004)

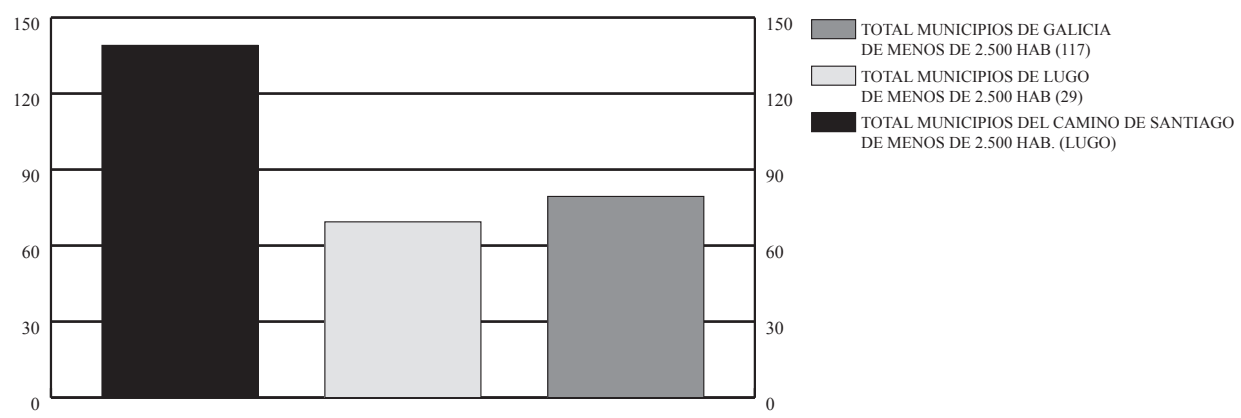

Fuentes: Anuario del Mercado Español Banesto, 1992; Anuario Comercial de España, 1998; Anuario Económico de España, 2001, 2002, 2005

Como se muestra en el Gráfico n 12 , entre 1991 y 2004, la evolución de licencias comerciales para los municipios del Camino entre 2500 y 4999 habitantes, resulta ligeramente superior a la alcanzada por el resto de municipios gallegos. Si bien durante la etapa 1991-1996, el porcentaje de crecimiento de la actividad comercial era bastante superior en los municipios por los que atraviesa la Ruta Francesa, esta tendencia se rompe en el periodo siguiente (1996-2001) para acentuarse todavía más en el periodo de estudio más reciente (2001-2004). 
Figura $\mathrm{n}^{\circ}$ 12. Crecimiento de licencias comerciales en los municipios del Camino de Santiago Francés entre 2.500 y 4.999 hab. (1991-2004)

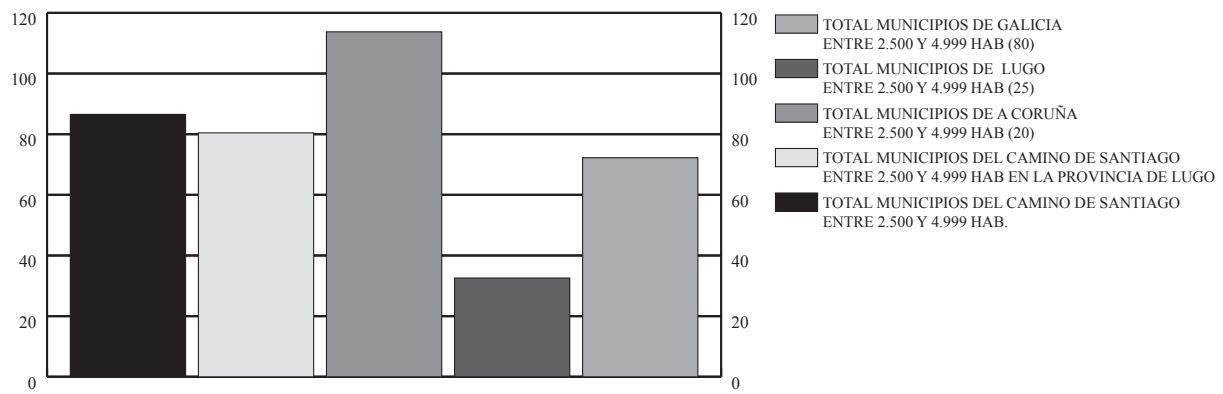

Fuentes: Anuario del Mercado Español Banesto, 1992; Anuario Comercial de España, 1998; Anuario Económico de España, 2001, 2002, 2005

En lo referente a la evolución del crecimiento de la actividad comercial de los dos municipios camineros que tienen una población de entre 5000 y 9999 habitantes (Figura $\mathrm{n}^{\circ} 15$ ) se observa que, de 1991 a 2004, el porcentaje de crecimiento de la actividad comercial para estos dos municipios lucenses es ligeramente superior a la de los municipios gallegos del mismo número de habitantes. Si bien su evolución era muy positiva entre 1991 y 1996 (superando la media regional y provincial), esta tendencia se empieza a desdibujar de 1996 a 2001 (en el que todavía detenta un porcentaje ligeramente superior a Galicia y Lugo) para confirmarse este descenso en el espacio de tiempo comprendido entre 2001-2004.

En lo referente a la evolución que presenta la variable relativa al número de licencias comerciales para el municipio lucense de Sarria (que posee entre 10.000 y 19.999 habitantes), entre 1991 y 2004, su porcentaje de crecimiento corresponde a un $86,91 \%$, dato superior al alcanzado por los municipios gallegos dentro de esta categoría $(56,61 \%)$ y de los de Lugo (44,18 \%). Sarria experimenta un importante porcentaje de crecimiento de esta variable de 1991 a 1996, tanto con respecto a Galicia como a Lugo pero empieza a manifestar a partir del periodo 1996-2001 una tendencia menos favorable que continúa en la etapa 2001-2004. 
Figura $\mathrm{n}^{\circ} 13$. Crecimiento de licencias comerciales de los municipios del Camino de Santiago Francés entre 5.000 y 9.999 hab. (1991 - 2004)

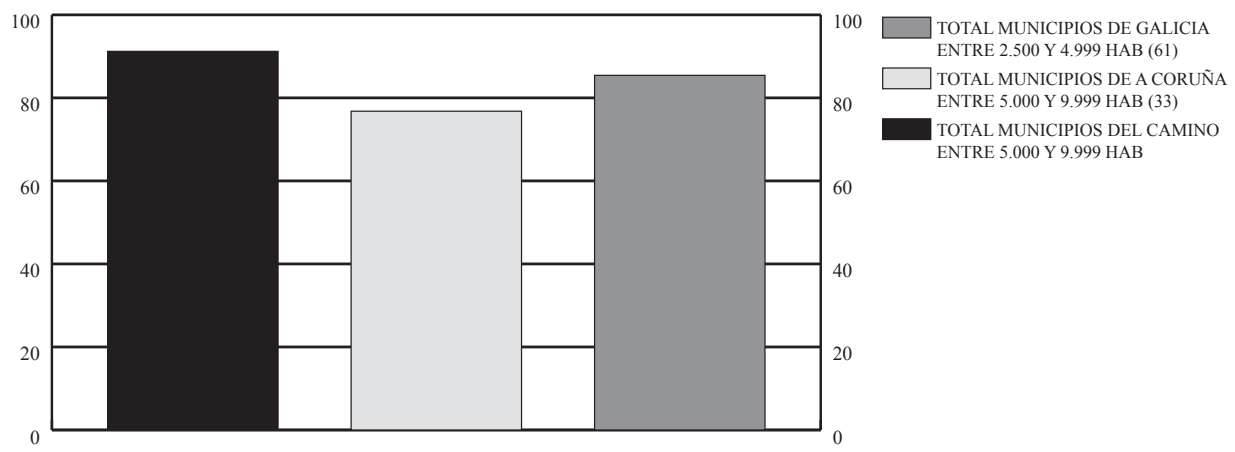

Fuentes: Anuario del Mercado Español Banesto, 1992; Anuario Comercial de España, 1998; Anuario Económico de España, 2001, 2002, 2005

De este modo, intentar valorar el éxito o fracaso del Camino desde el punto de vista económico, resulta complicado puesto que, si bien este grupo de municipios jacobeos entre 1.991 y 2.004 presentan una tendencia favorable (comparados con la media gallega y la de sus respectivas provincias) en cuanto a la actividad comercial, esta evolución positiva no continúa la misma propensión a partir de 1.996. Por tanto, cabe dudar de la potencialidad del Camino como fuente de revitalización económica de estos municipios puesto que sus repercusiones se ponen de manifiesto a una escala muy reducida.

\section{V.4. ANÁLISIS DE LA VARIABLE ÍNDICE TURÍSTICO}

Tabla $n^{\circ} 7$. Distribución del índice turístico en los municipios del Camino de Santiago Francés $\left(1991-2003^{7}\right)$

$\begin{array}{lcccc} & \begin{array}{c}\text { Índice } \\ \text { turístico } 1991\end{array} & \begin{array}{c}\text { Índice } \\ \text { turístico } 1996\end{array} & \begin{array}{c}\text { Índice } \\ \text { turístico 1999 }\end{array} & \begin{array}{c}\text { Índice } \\ \text { turístico 2003 }\end{array} \\ \text { Arzúa } & - & 3 & 3 & 6 \\ \text { Melide } & - & 5 & 4 & 3 \\ \text { Pino, O } & - & 1 & 1 & 3 \\ \text { Guntín } & 2 & 1 & 1 & 1 \\ \text { Monterroso } & 1 & 1 & 1 & 1 \\ \text { Nogais, As } & 3 & 6 & 6 & 4\end{array}$

7 Los datos que no aparecen en la tabla no existen debido a que algunos municipios no superan la franja que establece el Instituto de Estudios de La Caixa de tener como mínimo 50 plazas hotelera para incluirlos en su Anuario 


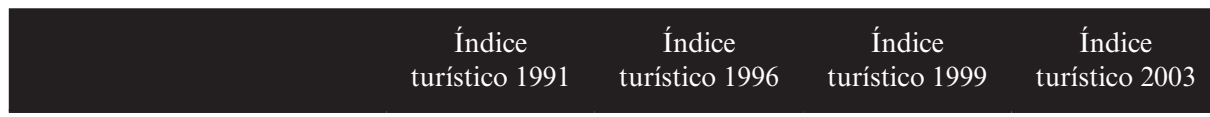

$\begin{array}{lllll}\text { Palas de Rei } & - & 2 & 3 & 3 \\ \text { Paradela } & - & - & 1 & 1 \\ \text { Páramo, O } & - & - & - & - \\ \text { Pedrafita do Cebreiro } & 2 & 6 & 7 & 5 \\ \text { Portomarín } & - & 4 & 9 & 6 \\ \text { Samos } & - & 2 & 2 & 2 \\ \text { Sarria } & 3 & 6 & 9 & 9\end{array}$

Triacastela

Fuentes: Anuario del Mercado Español Banesto, 1992; Anuario Comercial de España, 1998; Anuario Económico de España, 2001, 2002, 2005

Tabla $\mathrm{n}^{\circ}$ 8. Crecimiento del índice turístico en los municipios del Camino de Santiago Francés (1991- 2003)

$\begin{array}{lcccc} & \text { Índice } & \text { Índice } & \text { Índice } & \text { Índice } \\ \text { Municipios del Camino de Santiago } & \text { Turístico } & \text { Turístico } & \text { Turístico } & \text { Turístico } \\ & 1991-1996 & 1996-1999 & 1999-2003 & 1991-2003\end{array}$

$\begin{array}{lcccc}\text { Arzúa } & & 0 & 100 & \\ \text { Melide } & & -20 & -25 & \\ \text { Pino, O } & -50 & 0 & 200 & -50 \\ \text { Guntín } & 0 & 0 & 0 & 0 \\ \text { Monterroso } & 100 & 0 & -33,33 & 33,33 \\ \text { Nogais, As } & & 50 & 0 & 0 \\ \text { Palas de Rei } & & 0 & 0 \\ \text { Paradela } & & & & \\ \text { Páramo, O } & 200 & 16,67 & -28,57 & 150 \\ \text { Pedrafita do Cebreiro } & & 125 & -33,33 & \\ \text { Portomarín } & & 0 & 0 & 200 \\ \text { Samos } & 100 & 50 & 0 & \\ \text { Sarria } & & & \end{array}$

Triacastela

Fuentes: Anuario del Mercado Español Banesto, 1992; Anuario Comercial de España, 1998; Anuario Económico de España, 2001, 2002, 2005 
Entre 1991 y 2003 (Tabla n ${ }^{\circ}$ 8), tan sólo un municipio da muestras de un crecimiento negativo del índice turístico: Guntín (-50\%). Monterroso no experimenta variación alguna y los otros tres municipios presentan una tendencia positiva: Sarria (200\%), Pedrafita (150\%) y As Nogais (33\%). Entre 1991 y 1996, únicamente Guntín $(-50 \%)$ continúa con la misma tendencia desfavorable, que permanecerá estable en las dos etapas posteriores. En este periodo (de 1996 a 1999) hay tres municipios con crecimiento positivo de este índice: Pedrafita (200\%), Sarria y As Nogais (ambos con variación del $100 \%$ ) siendo Melide (-20\%) el único municipio en el que desciende el índice turístico, puesto que en la mayoría no se experimentan variaciones, únicamente en cuatro municipios evoluciona favorablemente, sobre todo en Portomarín. No obstante, entre 1999 y 2003, sólo experimentan crecimiento positivo de esta variable O Pino (200 \%) y Arzúa (100\%), muestran signos de empeoramiento As Nogais, Melide, Pedrafita y Portomarín, manteniéndose el resto de municipios sin variaciones.

Cabe recordar que, si bien se partía de la idea de que el flujo creciente de peregrinos generaría dinamismo económico introduciendo alternativas como la del turismo rural, los datos referidos a la evolución del índice turístico para los municipios por los que atraviesa el Camino Francés, ponen de manifiesto un comportamiento poco uniforme siendo, por tanto, difícil confirmar si esta Ruta tiene o no un papel importante en su dinamización turística. Aunque en los primeros años (de 1991 a 1996) se confirma una tendencia positiva, a partir de 1996 los municipios examinados continúan trayectorias irregulares en la evolución de este indicador.

En definitiva, a pesar de indudables elementos positivos, el Camino no genera una dinamización turística demasiado importante sobre estos municipios. El tránsito de miles de peregrinos es sólo un paso hacia el destino, Santiago de Compostela, sin que se refleje demasiado crecimiento en el índice turístico de estas localidades. Por otra parte, se caracteriza por ser un turismo de intensidad baja y con un marcado carácter estacional, excepto en los Años Santos.

\section{CONSIDERACIONES FINALES}

Los espacios rurales han sufrido en los últimos años los efectos de la industrialización-terciarización y de la urbanización a través de una pérdida de población y de un descenso del peso de la agricultura y otras actividades primarias; por otro lado, hacia finales del siglo XX, la percepción de lo rural empieza a sufrir algunas modificaciones y se comienza a promover una clara revalorización y cambio de actitud hacia estos espacios que dan cuenta del fenómeno de la neorruralidad y que consideran a este espacio como multifuncional en el que, además de actividades netamente agropecuarias, se puedan dar otros procesos productivos.

Dentro de esta filosofía de aprovechamiento integral de los recursos endógenos, el turismo en estas áreas rurales se perfila como una actividad económica sus- 
ceptible de formar parte, en muchos casos, de planes de desarrollo. De este modo, en los últimos años se lleva a cabo una política de fomento de la actividad turística en municipios rurales dotados de numerosos recursos naturales y culturales pero muy deteriorados desde el punto de vista demográfico y económico.

En base a estos argumentos, resulta relevante destacar que, en torno al Camino de Santiago han ido surgiendo en los últimos años una serie de ideas relativas a su indiscutible papel en el desarrollo económico y social de Galicia, por tanto, revalorizar el Camino en un momento en que la mayoría de las regiones que atraviesa se debaten entre la despoblación y el desmantelamiento del medio rural, debería suponer nada menos que fijar a esa población para que, con la complementariedad de las actividades en el sector servicios, pudieran encontrar una alternativa revitalizadora.

A tal efecto, se ha intentado en la presente investigación establecer el grado de importancia del Camino de Santiago y su capacidad para viabilizar procesos de desarrollo endógeno y generar las sinergias necesarias para que el proceso sea sostenible. Se considera de vital importancia conocer, analizar y evaluar la incidencia del Camino de Santiago en el desarrollo de estos espacios rurales, puesto que el conocimiento de tales variables facilitará la planificación y las estrategias de promoción y regulación de esta ruta milenaria

No obstante, debe ponerse en evidencia que, si bien generó en los momentos iniciales cierta euforia, debe valorarse con mayor cautela y dentro de unos parámetros más objetivos puesto que, con todo, el Camino de Santiago no llega a ser un factor verdaderamente importante en el desarrollo social y económico de las localidades rurales que atraviesa aunque, por otra parte, no caben dudas respecto a que la afluencia coyuntural de peregrinos, fundamentalmente en los Años Xacobeos, sea un pequeño complemento al desarrollo de estos municipios rurales examinados.

Ni siquiera los millones de euros recibidos vía programas comunitarios de desarrollo están consiguiendo frenar la tendencia al vaciado poblacional. Es evidente que se producen durante estos años etapas de crecimiento de la actividad comercial o de la cuota de mercado pero sin generar sinergias que provoquen un cambio de tendencias; tampoco el desarrollo turístico de las zonas afectadas por el Camino Francés no se ha visto específicamente favorecido por la política de inversiones comunitarias puesto que las repercusiones de las inversiones del Xacobeo no parecen ofrecer resultados demasiado importantes.

Esta exposición de cautela no significa, sin embargo, un menosprecio de las oportunidades del Camino de Santiago, denota más bien, un propósito de matizar las excesivas expectativas creadas. A pesar del espejismo que supone el turismo rural y los programas de desarrollo del Xacobeo, la mayoría de estos municipios siguen sumidos en una profunda crisis económica y demográfica. Cabe pensar que algo falla cuando la evolución no presenta un crecimiento satisfactorio en ninguna de las variables analizadas: población, comercio, capacidad de consumo y el propio turismo.

Por otra parte, una aproximación a la evolución del desarrollo de estos municipios permite observar que no es posible hablar de pautas comunes para las regiones 
agrupadas bajo el epígrafe de municipios del Camino Francés en lo referente a la dinámica socioeconómica, siendo los principales factores de diferenciación de esta evolución: el tamaño de los propios núcleos poblacionales, su dinámica demográfica, su localización más o menos cercana a vías de comunicación y su potencialidad económica.

En definitiva, cabe poner de relieve que las repercusiones del Camino desde el punto de vista socioeconómico analizado, no han sido todo lo efectivas que cabría esperar puesto que a pesar de indudables elementos positivos, esta Ruta no está logrando generar una dinámica de crecimiento sobre los municipios que atraviesa.

Por otro lado, conviene tener presente que la implantación de las actividades turísticas en el medio rural tiende a presentarse con frecuencia como la solución única a los problemas sociales y económicos de las regiones más deprimidas y, este tipo de afirmaciones, genera unas expectativas desmedidas que parece necesario matizar. En este sentido, sería oportuno considerar el hecho de que el turismo es una medida sectorial que por si sola no puede subsanar los problemas de las áreas rurales puesto que la cuestión de la despoblación y del retraso económico urge soluciones globales y no parciales.

De este modo, la Ruta Jacobea puede ser considerada como un complemento que puede aportar importantes beneficios en el futuro y ofrecerse como uno de los pilares en los que apoyar la rehabilitación social y económica de estos pueblos. Por tanto, el Camino de Santiago no puede ser considerado en sí mismo como el motor del desarrollo.

En definitiva, la revitalización del Camino de Santiago, desde el punto de vista socioeconómico analizado, no ha sido todo lo positiva que cabría esperar puesto que las repercusiones de estas inversiones parecen no ser demasiado importantes, puesto que a pesar de indudables elementos positivos, el Camino de Santiago no está generando una dinámica de crecimiento sobre las áreas rurales que atraviesa.

A la vista de los resultados, se puede afirmar que los efectos del Camino Francés no han sido suficientes para invertir la tendencia decreciente de la población de los núcleos rurales por los que atraviesa, que continúan el proceso de despoblamiento. De igual modo, se aprecia en lo referente a la evolución de la actividad comercial y del desarrollo turístico, la insuficiencia de los efectos del Camino como factor de desarrollo local pero, antes de dar una respuesta definitiva, es preciso añadir que, a partir de los resultados obtenidos, se hace necesario un análisis de las relaciones causales de lo ocurrido mediante una evaluación estratégica.

\section{BIBLIOGRAFÍA}

ÁLVAREZ SOUSA, A. (2005): "La contribución del turismo al desarrollo integral de las sociedades receptoras. Aspectos teórico-metodológicos", Política y Sociedad, 42 (1): 57-84. 
ÁlVAREZ SOUSA, A. (dir.) (1999): Homo peregrinus. Santiago de Compostela: Ed. Xerais de Galicia.

BLANCO, R.; GARRIDO, S. (coords.) (1994): Análise da Procedencia e Características da Afluencia Turística a Santiago no Xacobeo 92. Santiago de Compostela: Xunta de Galicia.

CALATRAVA REQUENA, J. (1999): "El turismo rural como recurso endógeno en el desarrollo local", En CANTO FRESNO, C (coord.)(1999) Desarrollo rural. Ejemplos europeos. Madrid: MAPA, pp. 67-91.

CALLEJO GALLEGO, J.; GUTIÉRREZ BRITO, J.; VIEDMA ROJAS, A. (2003): Análisis empírico de la demanda turística. Madrid: Ed. Ramón Aceres.

CALS, J; CAPELLÁ, J; VAQUÉR, E. (1995): El turismo en el desarrollo rural de España. Madrid: Ministerio de Agricultura, Pesca y Alimentación.

CANTO FRESNO, C. (Coord.) (1999). Desarrollo rural. Ejemplos europeos. Madrid: MAPA.

CID FERNÁNDEZ, X. M. (1999): Actores sociais e factores de cambio no medio rural. Universidade de Vigo.

GARCÍA COSTOYA, C. (1999): Las peregrinaciones jacobeas. Madrid: San Pablo.

GARCÍA DOCAMPO, M. (2003): A construcción social do territorio galego. Santiago de Compostela: TresCtres Editores.

GONZÁLEZ FERNÁNDEZ, M. (2002): Sociología y ruralidades. La construcción del desarrollo rural en el valle de Liébana. Madrid. MAPA.

GONZÁLEZ FERNÁNDEZ, M. (1999): “O turismo rural nas novas mitologías de desenvolvemento rural” en CID FERNÁNDEZ, X. M. (1999) Actores sociais e factores de cambio no medio rural. Universidade de Vigo, pp.: 135-150.

HERNÁNDEZ BORGE, J; DÍAZ FDEZ., J. A.; PATIÑO ROMARÍS, C. A. (coord.) (2000): O turismo en Galicia. Potencialidades endóxenas de desenvolvemento urbano e económico. Diputación Provincial de Pontevedra

IVARS BAIDAL, J.A. (1997): “¿Constituye el turismo la mejor apuesta para el desarrollo rural?", en VALENZUELA RUBIO, M. 1997. Los turismos de interior. El retorno a la tradición viajera. Universidad autónoma de Madrid, pp.: 675-683

IVARS BAIDAL, J.A. (2003): Planificación turística de los espacios regionales en España, Síntesis, Madrid.

KADT, E. DE (1979): Turismo: ¿pasaporte al desarrollo? Madrid: Endymion.

LÓPEZ OLIVARES, D. (2003): “El desarrollo turístico integrado en los espacios rurales de interior: su aplicación al producto de salud", Cuadernos de Turismo, (11): $107-126$

LÓPEZ PALOMEQUE, F. (1993): "Diversidad de tipologías que vertebran el Camino de Santiago" en DE TORRES LUNA, M. P.; PÉREZ ALBERTI, A.; LOIS GONZÁLEZ, R. C. (1993) Los Caminos de Santiago y el territorio. Congreso Internacional de Geografía. Xunta de Galicia. Santiago de Compostela, pp.: 801-823.

MÁRQUEZ FERNÁNDEZ, D. (2002): Nuevos horizontes en el desarrollo rural. Universidad Internacional de Andalucía: Akal. 
MARTÍNEZ ROGET, F. (2004): Turismo rural en Galicia. Contribuciones al desarrollo sostenible. Xunta de Galicia. Consellería de Cultura, Comunicación Social e Turismo. Dirección Xeral de Turismo. Santiago de Compostela

MATHIESON, A., WALL, G. (1990): Turismo. Repercusiones económicas, físicas y sociales. México: Ed. Trillas.

McINTOSH, R. W.; GOELDNER, CH. R.; BRENT, J. R. (1991): Turismo. Planeación, administración y perspectivas. México: Ed. Limusa.

PARDELLAS DE BLAS, X. (2000): "O papel do turismo no desenvolvemento de espacio rural” en HERNÁNDEZ BORGE, J; DÍAZ FDEZ., J. A.; PATIÑO ROMARÍS, C. A. (coord.) (2000) O turismo en Galicia. Potencialidades endóxenas de desenvolvemento urbano e económico. Diputación Provincial de Pontevedra, pp.: 115-132.

PEDREÑO, A.; MONFORT, M. (1996): Introducción a la economía del turismo en España. Madrid: Ed. Civitas.

PORCAL GONZALO, Ma .C. (2003): "Propuestas de actuación para el desarrollo turístico sostenible de una comarca rural de media montaña”, Investigaciones Geográficas, 32: 65-90.

PRECEDO LEDO, A. (2004): Nuevas realidades territoriales para el siglo XXI: desarrollo local, identidad territorial y ciudad difusa. Madrid: Editorial Síntesis.

PRECEDO LEDO, A. et. al. (2007): "El turismo cultural como factor estratégico de desarrollo: el Camino de Santiago”, Estudios Geográficos, Vol. LXVIII, (262): 205-234.

ROYO VELA, M.; SERAROLS TARRÉS, C. (2005): “El turismo rural-cultural: un modelo de gestión del marketing turístico a nivel local, basado en la medida de la imagen del turismo", Cuadernos de turismo, (16): 197-220.

SANTOS SOLLA, J.M. (1993): «El Camino de Santiago como alternativa turística de Galicia», Congreso Internacional de Geografía: Los Caminos Santiago y el territorio. Santiago de Compostela: Xunta de Galicia. pp. 783-799.

SANTOS SOLLA, X. (1999): "Mitos y realidades del Xacobeo", Boletín de la Asociación de Geógrafos Españoles, 27: 103-117.

SANTOS, X. (2002): «Pilgrimage and Tourism at Santiago de Compostela», Tourism Recreation Research, 27 (2): 41-50.

SANTOS SOLLA, X. (2006): «El Camino de Santiago: turistas y peregrinos hacia Compostela», Cuadernos de Turismo, (18):135-150.

VALENZUELA RUBIO, M. (1997): Los turismos de interior. El retorno a la tradición viajera. Universidad autónoma de Madrid.

VERA, F., LÓPEZ PALOMEQUE, F., MARCHENA, M., ANTÓN, S. (1997): Análisis territorial del turismo. Barcelona: Editorial Ariel Geografía. 